\title{
ADOÇÃO: UMA ANÁLISE ASSISTEMÁTICA DA LITERATURA CIENTÍFICA BRASILEIRA
}

Adoption: an unsystematic analysis of the brazilian scientific literature

\author{
Sanai da Silva ${ }^{1}$; Marcel da Luz Pessoa da Silva ${ }^{2}$; Felipe Biasus ${ }^{3}$
}

\footnotetext{
${ }^{1}$ Acadêmica do Curso de Psicologia da Universidade Regional Integrada do Alto Uruguai e das Missões - Câmpus de Erechim (URI).E-mail: sanai.silva@outlook.com

${ }^{2}$ Acadêmico do Curso de Psicologia da URI - Câmpus de Erechim.

${ }^{3}$ Professor e Coordenador do Curso de Psicologia da URI - Câmpus de Erechim.
}

RESUMO: Este estudo teve como objetivo realizar uma revisão assistemática da literatura nacional sobre adoção. Para isso, foi realizado um levantamento bibliográfico onde foram selecionados 45 artigos, publicados entre 2008 e 2017, encontrados através dos descritores "adoção", "percepção + adoção" e "representação social + adoção". Os artigos selecionados foram agrupados nas categorias: Especificidades da adoção (Contempla artigos que abordam adoções "atípicas", adoções que fogem do perfil padrão de adotado); Relação adotiva (Abrange artigos que exploram a construção do relacionamento entre o adotante e o adotado); Adultos (Artigos que focam na visão dos pais/ família, biológicos ou adotivos e outros adultos, sobre a adoção) e Representações sociais (Inclui artigos que tratam sobre como se dá a ressignificação da adoção). Os resultados apontam que há conexão entre todas as categorias, ou seja, entre adotar um perfil atípico, elaborar uma relação adotiva saudável e naturalizar a experiência da adoção com a ressignificação proporcionada por grupos de apoio e a promoção de discussões sobre o assunto. Conclui-se que há necessidade de realizar estudos com diferentes públicos sobre a representação da adoção, a fim de identificar como o tema é pensado e possibilitar orientações e difusão de informação com vistas ao desenvolvimento de uma cultura da adoção.

Palavras-chave: Adoção. Relação familiar. Pais por adoção. 
ABSTRACT: The aim of this study was to conduct an unsystematic review of the national literature on adoption. For this, a bibliographic survey was carried out, in which 45 articles were selected, published between 2008 and 2017 , found through the descriptors "adoption", "perception + adoption" and "social representation + adoption". The selected articles were grouped into categories such as: Specificities of Adoption (Articles that address "atypical" adoptions, adoptions that do not follow the adopted standard profile); Adoptive Relationship (Articles that explore the construction of the relationship between the adopter and the adopted); Adults (Articles that focus on the view of biological or adoptive parents/family, and other adults, on adoption) and Social Representations (articles that deal with how the resignification of adoption takes place). The results indicate that there is a connection between all categories, that is, between adopting an atypical profile, developing a healthy adoptive relationship and naturalizing the experience of adoption with the reframing provided by support groups and the promotion of discussions on the subject. It is concluded that there is a need to carry out studies with different audiences on the representation of adoption, in order to identify how the theme is thought and to enable guidance and dissemination of information furthering to develop an adoption culture.

Keywords: Adoption. Family relationship. Foster Parents

\section{Introdução}

A prática da adoção tem integrado as sociedades humanas há muito tempo. As mais antigas civilizações que conhecemos contemplam alguma regulamentação de situações de adoção que atendiam a diferentes propósitos, como a escolha de Faraós no Egito e o fortalecimento de alianças na criação de linhagens hereditárias mais convenientes em Roma. Tais regulamentações foram encontradas no Egito, Índia, China, Grécia e Roma, sendo a mais antiga presente no Código de Hammurabi (2800 a.C.). Desse modo, parece razoável afirmar que não houve nenhuma época histórica sem alguma prática relativa à adoção. Entretanto, se as significações sobre adoção, suas práticas e regulamentações legais sofreram inúmeras mudanças ao longo da história, elas sempre atenderam aos interesses dos adultos e das sociedades, sendo as necessidades das crianças pouco consideradas. Por isso, podemos afirmar que vivemos de algumas décadas para cá um processo novo. Uma era marcada pelo melhor interesse da criança, filosofia internacional que norteia as regulamentações e políticas de atenção à criança em vários países (COSTA; ROSSETTI-FERREIRA, 2007).

Os mesmos autores referem que, no Brasil vimos surgir um movimento por uma nova cultura de adoção, a qual preconiza que se deve buscar uma família para uma criança e não uma criança para uma família. Com o apoio de organizações sociais e de técnicos do judiciário, essa nova cultura da adoção busca fomentar adoções diferenciadas, chamadas adoções modernas, como as adoções tardias, de grupos de irmãos, de crianças com necessidades especiais, portadoras do vírus HIV e as adoções inter-raciais. No entanto, essa nova cultura da adoção comporta um 
novo projeto de família, de maternidade e de paternidade e atribui novos sentidos ao ser pai e mãe. Pressupõe uma família que aceite o diferente, a alteridade, que não só lide com projetos de filiação alternativos, mas que efetivamente adote o diferente.

Percebe-se, no entanto, que, mesmo com as modificações propostas nessa nova cultura da adoção, um grande número de crianças ainda se encontra institucionalizada, à espera de adoção eventual, que tende a se tornar cada vez mais improvável à medida que o tempo passa e elas se tornam mais crescidas. Muitas crianças abrigadas, com mais de dois anos de idade, já têm compreensão suficiente para nutrir expectativas ansiosas de serem escolhidas e acolhidas por casais interessados, mas na maior parte das vezes, permanecem frustradas, porque os casais brasileiros preferem bebês (PONTES; CABRERA; FERREIRA; VAISBERG 2008).

O estudo realizado por Weber (2003) traçou o perfil sobre adoção e família adotiva no Brasil e destacou aspectos relacionados à motivação para adoção registrando que a principal motivação para adoção estaria ligada à incapacidade de ter filhos próprios (50\%), tendo os pais adotivos destacado que preferiam seguir o padrão da biologia e passar pela experiência de cuidar do bebê recém-nascido. Sabe-se que, apesar da relevância atribuída à questão humanitária que envolve adotar uma criança, o que prevalece na sua busca é a solução para a aflição e angústias decorrentes da infertilidade e para seus desejos de ter um filho no sentido de livrar o casal da solidão e do narcisismo ameaçado (PIVA, 2002).

Cassin e Jacquemin (2001) descrevem um perfil semelhante ao de Weber, ao fazer um levantamento de 502 pessoas que procuraram o Setor de Serviço Social e Psicologia da Vara da Infância e da Juventude da Comarca de Ribeirão Preto com intenção de adotar, entre 1986 e 1999. A maioria era casada ou ama- siada (93,8\%); entre 30 e 39 anos; brancos; com ensino fundamental incompleto ou com ensino médio; e sem filhos (69,3\%). Quanto à criança que desejavam, 92\% queriam uma criança recém-nascida ou até um ano de idade; 47,3\% não tinham preferência pelo sexo, mas dentre os que demonstram preferência, a maioria desejava menina; $89,7 \%$ desejavam uma criança branca; $92,7 \%$ aceitavam somente uma criança saudável (apenas uma pessoa aceitava crianças soro positiva ao HIV); e 57,5\% não adotariam irmãos.

Com relação à adoção tardia, ou seja, crianças acima de dois anos, Ebrahim (2001) aponta que os adotantes possuem um perfil diferenciado em relação aos adotantes "clássicos". Esses adotantes tardios muitas vezes não estão em uma relação matrimonial, já possuem filhos biológicos e costumam ser mais maduros que o adotante convencional. Entende-se que essa maturidade, somada a uma estabilidade econômica e emocional, facilita que a motivação para adotar se volte para um lado altruísta e não tão concentrado nas necessidades do adotante em si.

Gilberti (1999) marca a diferença entre os filhos adotivos e os biológicos, salientando que esta deve ser sempre considerada. $\mathrm{Na}$ visão narcisista, deve-se reconhecer como diferente a ruptura da continuidade biológica que se introduz o adotivo, e os lutos que são parte desta história. Há, inegavelmente, um reposicionamento a ser feito e isso exige uma elaboração particular. Para Borba (2015), existe o perigo de que, se os pais não forem capazes de fazer um luto adequado do filho biológico desejado, a extensão do seu apego ao filho adotivo pode ser afetada.

Quando Szejer e Stewart (1997) exploraram o lugar ocupado por um determinado filho em uma família, os autores quiseram mostrar que lutar contra as imagens que os "mortos" (filhos que morreram ou que simplesmente não nasceram) deixaram e contra as marcas que ficaram nos sobreviventes ao 
luto, é uma tarefa muito difícil. O processo de reestruturação de uma família diante de uma perda, seja real ou simbólica, ocorre quando os lugares são redistribuídos no momento em que um novo membro chega.

Para Gilbert (1999), existe uma diferença entre aqueles casais conscientes da esterilidade, que buscam a adoção, posicionando o adotivo substitutivamente desde o primeiro dia de sua guarda, como se fosse parte da família, e àqueles que procuram a adoção por "via das dúvidas", podendo o adotivo vir a ser excluído em caso de fecundação. São essas possibilidades de exclusão como a história de abandono e diferenças do filho adotado que embasam as crenças de que crianças adotadas apresentam um grande risco de mau ajustamento e de que facilmente a saúde mental das pessoas adotadas se diferencie da população em geral tem gerado uma preocupação intensa nos pesquisadores. Temas como o ajustamento e adaptação entre pais e filhos adotivos (HOKSBERGEN; WALRAVEN; KOHNSTAMM, 1997; BRODZINSKY; SCECHTER, 1984), os transtornos psiquiátricos e acadêmicos em crianças e adolescentes adotivos (TAYLOR; RUTTER; HERSOV, 1995) e a adoção internacional e inter-racial (SHIFF; ZORAN; SHULMAN, 1997) são alguns exemplos sobre a atenção dos pesquisadores aos aspectos que procedem o período da adoção.

Pensando sobre toda essa discussão em torno da adoção, este trabalho de revisão tem por objetivo analisar como o assunto está sendo entendido e vivenciado pela sociedade e seus indivíduos; e como pode ocorrer sua ressignificação visando a uma adequação à nova realidade que está sendo proposta, onde o interesse da criança ou jovem a ser adotado é priorizado, propiciando uma adoção efetiva.

O presente estudo integra o projeto de pesquisa "Representação social de adoção: o que pensam crianças, adolescentes e adultos", sendo que nesta etapa se seguiu um delinea- mento de pesquisa de revisão bibliográfica da literatura nacional, não sistemática, exploratória e descritiva. Os descritores utilizados na busca de artigos foram "adoção", "percepção + adoção" e "representação social + adoção". A primeira lista de artigos escolhidos se deu a partir do título dos mesmos, e a lista final após a leitura dos resumos, chegando ao total de 45 artigos, publicados entre 2008 e 2017. Destes, foram elaborados fichamentos de leitura a fim de discutir em grupo e organizar a análise e integração das informações sobre o assunto da pesquisa, a adoção. Assim, se possibilitou um melhor entendimento sobre a mesma, desenvolvendo-se uma visão geral para o projeto de pesquisa anteriormente citado. Considerando o universo dos 45 artigos, quanto ao tipo de pesquisa, 9 são bibliográficas, 18 são empíricas, 5 são documentais, 11 são estudos de caso e 2 são referentes à validação psicométrica.

\section{Resultados e Discussão}

Partindo dos fichamentos realizados, foi feito um levantamento de categorias com base em tópicos recorrentes em vários artigos, elencando-as em subcategorias para melhor compreensão da temática em estudo (Tabela 01). Como os artigos abordam variadas facetas do assunto adoção, e um mesmo artigo traz tópicos diversos, as categorias aqui criadas acabam por ser bastante abrangentes, buscando contemplar essa gama de informações. Portanto, um artigo pode estar alocado em mais de uma categoria e/ou subcategoria. Com relação ao que comporta cada uma das categorias e suas subdivisões, tem-se:

\section{Especificidades da Adoção}

Contemplando artigos que abordam adoções "atípicas", ou seja, aquelas adoções que fogem do perfil padrão de adotado (bebê 
caucasiano, sem complicações de saúde). As subcategorias formadas são adoção internacional (quando o adotante é estrangeiro), de crianças maiores (a partir dos 5 anos de idade), essencial (adotado com alguma deficiência física/mental ou doença crônica) e $d e$ irmãos (dois ou mais adotados que vieram da mesma família biológica).

Assim sendo, no que tange a esta categoria, Mozzi e Nuernberg (2016) discorrem sobre como a adoção de criança com deficiência, por vezes não está associada a uma escolha especificamente delineada pelos adotantes, mas sim, como um produto de processo de vínculo. Vários casais que participaram da pesquisa vivenciaram, inicialmente, o apadrinhamento das crianças, criando um envolvimento prévio com as mesmas e compreensão da condição delas. Essa mesma perspectiva é apresentada por Apolinário e Antunes (2015), quando se trata da adoção de crianças ou jovens soropositivos (alvos de estigmas e preconceitos fortes), pois é com informação e preparação que se desmistifica a situação perante a sociedade, além de citarem a importância de se realizar mais estudos específicos sobre o assunto, com o intuito de ampliar cada vez mais as discussões acerca desse tipo essencial de adoção. Vale ressaltar que estes dois estudos foram os únicos que abordaram a questão da adoção essencial de forma específica.

Sobre adoção internacional, o perfil de jovem ou criança adotado já é mais diferenciado por conta da limitação (brasileiros têm preferência na fila de espera), e os ado-

Tabela 01 - Categorização dos artigos que compõem a revisão bibliográfica

\begin{tabular}{|c|c|c|}
\hline Categoria & Subcategoria & $N^{o}$ de artigos \\
\hline & Adoção internacional & 3 \\
\hline Especificidades da & Adoção de crianças maiores & 10 \\
\hline \multirow[t]{2}{*}{ adoção } & Adoção essencial & 2 \\
\hline & Adoção de irmãos & 2 \\
\hline \multirow{5}{*}{ Relação adotiva } & Construção de vínculo & 11 \\
\hline & Identidade do adotado & 6 \\
\hline & Omissão da condição & 8 \\
\hline & Auxílio psicoterapêutico & 3 \\
\hline & Motivação para adoção & 9 \\
\hline \multirow{4}{*}{ Adultos } & Paternidade/Maternidade & 13 \\
\hline & Devolução ou abandono & 5 \\
\hline & Família extensa & 3 \\
\hline & Adultos sem relação & 8 \\
\hline \multirow{4}{*}{ Representações sociais } & Contexto histórico & 9 \\
\hline & Construção de significados & 15 \\
\hline & Ampliar discussão & 11 \\
\hline & Grupo de apoio & 9 \\
\hline
\end{tabular}


tantes têm consciência dessa necessidade de ampliar seu perfil, portanto, trabalham uma reconstrução do que é uma família e do que é ser mãe/pai (MERÇON-VARGAS; ROSA; DELL'AGLIO, 2014). Além disso, Couto (2014) refere que a adoção, por si só, já faz parte de um processo de adaptação pautado em dificuldades iniciais. Quando se refere à adoção internacional essas dificuldades tendem a aumentar pelo fato de que o adotado é levado para um país diferente, com cultura, língua, comidas, costumes diferentes quando comparado ao país no qual já estaria habituado.

Em relação à subcategoria adoção de crianças maiores, pode-se perceber que tende a ser uma adoção atípica, por não se configurar como a primeira opção de indivíduos/ casais que adotam, os quais tendem a preferir um filho recém-nascido. Além disso, esta especificidade de adoção tende a ser permeada de receios pelos adotantes, no que se refere à saúde física e emocional das crianças bem como à vivências anteriores na família biológica e na instituição (DUGNANI; MARQUES, 2011). Otuka, Scorsolini-Comin e Santos (2009) encontraram em seus estudos que a maioria dos casais que adotam crianças maiores já têm, pelo menos, um filho biológico. Com isso, esses casais foram entendidos como sendo emocionalmente mais estáveis e altruístas.

No que diz respeito a como este processo é vivenciado, estudos encontraram que podem existir maiores dificuldades por necessitar de uma adaptação tanto dos pais quanto das crianças (MERÇON-VARGAS; ROSA; DELL'AGLIO, 2011). Para as crianças, as possíveis vivências prévias de abandono, perdas e frustrações podem causar dúvidas, insegurança e cautela na aproximação com os pais adotivos, o que tende a dificultar o vínculo (SILVA, 2010; COUTO, 2014). Porém, esta possibilidade de adoção não pode ser vista como um sinônimo a dificuldades, pois se trabalhado as demandas parentais e filiais, ao longo do processo, pode vir a não apresentar problemas (SILVA; BENETTI, 2015).

\section{Relação Adotiva}

Abrange artigos que exploram a construção do relacionamento entre o adotante e o adotado. Compõe as subcategorias construção de vínculo (como se dá o desenvolvimento do vínculo afetivo entre as partes), identidade do adotado (a construção do "eu" da criança ou jovem adotado), omissão da condição (revelação, ou não, da condição de adotado) e auxílio psicoterapêutico (quando há ajuda psicológica para uma melhor relação e desenvolvimento do vínculo).

No que diz respeito a esta categoria, o desenvolvimento de um vínculo afetivo entre pais e filhos adotivos deve ser construído aos poucos, pois tende a ser um processo marcado por mudanças que irão ocorrer tanto na vida dos pais quanto na dos filhos adotivos (COUTO, 2014). Além disso, alguns estudos caracterizaram esta fase com limitações e dificuldades para o adotante e para o adotado. Quando a motivação para adoção é a infertilidade, esses pais presenciam um processo de luto pelo filho que não puderam ter, sendo que muitas vezes passaram por tratamentos que foram fracassados e isso tudo tende a ter uma carga emocional. Dependendo como isso é vivenciado pelos pais, pode vir a interferir na construção do vínculo. Para o adotado, este possui pais biológicos, passou por uma situação de abandono ou de rejeição e viveu em uma instituição por um tempo, no qual o modelo de relação é diferente (SONEGO; LOPES, 2009; BAPTISTA; SOARES; HENRIQUES, 2013). Sendo assim, essas crianças, quando introduzidas a um ambiente familiar novo, tendem a apresentar dificuldade em aceitar regras e dificuldades em se adaptar com as rotinas daquela família, sendo que 
por essas crianças apresentarem um histórico de abandono, algumas vezes sucessivos, muitos comportamentos existem como uma maneira inconsciente de testar esses pais para assim possuírem maior segurança de que não vão ser abandonados novamente (BORTOLATTO; LOOS; DELVAN, 2016; COUTO, 2014). Todos esses comportamentos tendem a trazer inseguranças nos pais adotivos em como devem educar seus filhos. Porém, alguns estudos corroboram para o entendimento de que a paciência, diálogo, determinação e coerência tendem a facilitar a vivência deste processo (MERÇON-VARGAS; ROSA; DELL'AGLIO, 2011; SANTOS et al., 2011).

Em relação à construção de uma identidade adotiva na criança/jovem adotado, existem estudos que retratam que esta tem seu início em uma narrativa coerente por parte dos pais adotivos, ou seja, é importante que exista um esclarecimento sobre a história do adotado, desde o início. Isso irá contribuir positivamente para um maior nível de felicidade e autoestima da criança/jovem adotado (DUCHARNE, 2012; LEVINZON, 2015). Além disso, uma adoção em que a criança/ jovem é tomada como um ser-objeto, ou seja, quando é escolhida por algumas características próprias que venham a atender somente $o$ desejo dos pais, é extremamente prejudicial para o desenvolvimento da mesma, já que não terá um lugar destinado a ela na família, que possibilitaria sua significação social, além dos efeitos dessa adoção na sua subjetividade (MACEDO, 2014). Dessa forma, entender seu lugar único dentro da estrutura familiar é algo muito pertinente para a criança/jovem adotado (OTUKA; SCORSOLINI-COMIN; SANTOS, 2009).

Sobre a omissão da condição, alguns autores encontraram em suas pesquisas que esta há uma dúvida corriqueira entre os pais adotantes contar ou não para a criança adotada sobre a sua origem, em uma tentativa de proteger esta através da omissão e qual seria o momento mais apropriado para a revelação (LEVINZON, 2015; OTUKA; SCORSOLINI-COMIN; SANTOS, 2012; LEVY; DINANA; PINBO, 2009). Os autores consentiram com a ideia de que é importante que a criança saiba da sua verdadeira história, pois essas buscam saber sobre si para construir sua identidade, e para isso não precisa haver um dia da revelação. Os pais podem permitir que este seja um assunto presente e falado dentro do ambiente familiar, deixando de ser uma questão encoberta (LEVINZON, 2015; BARBOSA-DUCHARNE; BARROSO, 2012). É de essencial importância que os pais permitam que a criança tenha uma comunicação aberta e sincera com esses. Isso irá contribuir para um melhor entendimento do seu "eu" (DANTAS; FERREIRA, 2015; DUCHARNE, 2012).

No que concerne à subcategoria "auxílio psicoterapêutico", os estudos encontrados se referiram mais às questões parentais como um preparo para a chegada da criança/adolescente. Pinto e Picon (2009) retratam que é importante que exista uma intervenção preventiva, no qual possam ser trabalhados com os pais que irão receber esta criança/ adolescente questões relacionadas as suas próprias crenças, assim como temas referentes a dificuldades de adaptação, formação do vínculo, revelação do segredo, estabelecimento de limites, para que após a efetivação da adoção estes estejam melhor preparados. Quando relacionados à criança/adolescente, a ajuda psicoterapêutica esteve mais associada a dificuldades destes na escola e não ao processo adotivo em questão (OTUKA; SCORSOLINI-COMIN; SANTOS, 2009).

\section{Adultos}

Artigos que focam na visão dos pais/ família, biológicos ou adotivos, e outros adultos, sobre o assunto adoção foram agrupados nesta categoria. As subdivisões que a 
compreendem são motivação para adoção (razões pelas quais o adotante toma a decisão de adotar), paternidade/maternidade (como é vivenciar a experiência de ser pai ou mãe adotivo), devolução ou abandono (quando ocorre entrega legal ou ilegal de criança, ou devolução de um adotado), família extensa (experiência de familiares que não compõem o núcleo familiar) e adultos sem relação (visão que pessoas têm sobre adoção, sem ter relação direta com ela).

Segundo Bortolatto, Loos e Delvan (2016), sempre há uma motivação para a concretização de uma adoção, sendo a mais corriqueira delas a infertilidade. A impossibilidade de gerar filhos, seja pela parte do homem ou da mulher, é amplamente encontrada na literatura como a motivação número um. Portanto, mesmo com a atualização dos estudos sobre adoção, essa variável se mantém constante. Outras motivações que costumam surgir são o desejo de ampliar o número de filhos e de não ficar sozinho. Como se pode observar, as motivações concentram-se quase em sua totalidade na realização de uma necessidade do(s) indivíduo(s) adotante(s). Ainda no estudo citado, se destacou que vários casais priorizam a estabilidade financeira antes de optar pela paternidade, fazendo com que muitas vezes estejam em idade avançada e a adoção surja como opção derradeira. Quando a adoção não pende tanto para o lado do adotante, a motivação costuma se desenvolver através do vínculo emocional criado pela adotado e adotante durante o processo de aproximação entre as partes. Todavia, esse vínculo pode extrapolar o âmbito emocional e se cercar de um sentimento de dever moral, uma obrigação perante a sociedade. $\mathrm{O}$ que também não é de todo saudável, pois entra no paradigma de adoção ser entendida como caridade (APOLINÁRIO; ANTUNES, 2015).

Sobre como os pais adotivos vivenciam a adoção, Sonego e Lopes (2009), em estudo realizado com mães adotivas, observaram uma idealização da maternidade, onde os filhos são percebidos como especiais, a experiência maternal como realizadora e seus parceiros como engajados. Não fora possível averiguar a fundo se toda essa visão positiva da experiência advém da idealização, do receio de demonstrar ambiguidades na vivência maternal. No entanto, se entende que este fator está atuando na subjetividade delas. No outro extremo, têm-se pais que vivenciam fantasias negativas em sua experiência, como o medo de perder o filho para os pais biológicos, medo de o filho ter "sangue ruim" ou procurar os "pais verdadeiros" quando crescer (MAUX; DUTRA, 2009; OTUKA; SCORSOLINI-COMIN; SANTOS, 2012). Já Costa e Kemmelmeier (2013) destacaram o "gestar na fila de espera", ou seja, como os adotantes vivenciam a espera da adoção, que é permeada de agonia, ansiedade e incertezas. É necessário ter paciência para enfrentar toda a burocracia, sendo esse processo descrito como "uma gravidez que nunca acaba".

Na subcategoria devolução ou abandono se destacou o estudo de Martins et al., (2015), realizado com profissionais da saúde. Algumas das profissionais entendiam entrega e abandono como sinônimos, o que influencia no atendimento que ofertam às mães, ficando o mesmo prejudicado. A dificuldade das mães em verbalizar a entrega, o receio do julgamento pela decisão e a falta de apoio no momento do nascimento do filho, podem ser fatores que levam estas a abandonarem seus filhos. Portanto, entender a diferença significativa entre entregar a criança e abandoná-la de fato é de extrema importância, tanto para um melhor cuidado da criança quanto para um mínimo de gentileza para a mãe.

Contudo, ainda há um segundo "abandono", quando os adotantes devolvem a criança pretendida. A culpa sempre acaba sendo direcionada à criança, seja por comportamentos inadequados ou relacionamento ineficaz. Os pais se isentam de qualquer parcela de 
contribuição para o insucesso da adoção. $\mathrm{O}$ que se percebe nesse tipo de caso são essas famílias confrontando a criança ideal com a real, que não corresponde inteiramente aos desejos alimentados pelos pais (LEVY; PINHO; FARIA, 2009).

Com relação à família extensa, Valério e Lyra (2014) discorrem sobre como os entendimentos desses familiares passam por uma constante tensão entre a cultura coletiva que se enraizou neles durante seu desenvolvimento e uma cultura pessoal construída progressivamente ao conviver com essa nova realidade de filiação, de família. Toda esta adaptação e reconstrução de significados provêm do fato desses familiares adentrarem em um "assunto desconhecido", o que também é observado na população em geral (subcategoria adultos sem relação), que não está familiarizada ao termo adoção e o vê como distante de si. De um lado há consciência de que a existência de crianças para adoção aponta uma grave problemática, mas por outro prevalece uma perspectiva na qual a criança - sempre entendida como abandonada - está aí para resolver o sofrimento daqueles que não podem ter filhos biológicos (PONTES et al, 2008). Muitas pessoas desconhecem como acontece o processo de adoção, gerando mitos e tabus e dificultando que mais indivíduos considerem adotar. Essa falta de informação, na sociedade em geral, é bastante prejudicial (SILVA, 2010).

\section{Representações Construídas}

Inclui artigos que tratam sobre como se dá a significação ou ressignificação da adoção. As subcategorias geradas foram contexto histórico (construção temporal de algum tópico referente ao universo da adoção); construção de significados (como questões pessoais e/ ou sociais influenciam no entendimento do assunto); ampliação da discussão (impor- tância de desmistificar o assunto através de mais estímulos, discussões e sensibilizações sobre adoção) e grupo de apoio (como forma de possibilitar a ressignificação de vários aspectos da adoção).

Elencado na subcategoria contexto histórico, artigo de Maux e Dutra (2010) relata a grande influência que a herança cultural de hipervalorizar laços sanguíneos tem sobre como se entende a filiação nos dias de hoje. A adoção é vista como uma filiação de segunda ordem, não legítima. Isto reitera a infertilidade ser a motivação número um para ocorrer uma adoção ao decorrer da história (SILVA; MESQUITA; CARVALHO, 2010). Esse entendimento histórico é importante para observar que as pessoas atribuem sentido e valor às coisas e objetos segundo a construção social dos mesmos. Não é apenas falta de informação sobre adoção ou preconceito pessoal, é também cultura compartilhada.

Muitas construções de significados sofrem influência de concepções pessoais, como o alto preconceito por adotantes em uma relação homoafetiva estável, atrelado a crenças religiosas e/ou moralistas (PEREIRA et al., 2013). Ou ainda a associação de entrega da criança pela mãe como um "ato monstruoso" como o abandono, visto a idealização de amor materno como algo intrínseco às mulheres (FARAJ et al., 2016).

Todos esses tópicos demonstram como o tema adoção necessita de muita desmistificação. Variados estudos apontavam que ampliar a discussão, seja com mais estudos explorando diferentes facetas do tema ou a disseminação do assunto na sociedade, é uma importante forma de construir um novo entendimento geral sobre a adoção em si (DUGNANI; MARQUES, 2011; COUTO, 2014; AYRES, 2016; FARAJ et al., 2016).

Outro modo assertivo de difundir o esclarecimento da adoção, apontado por outros estudos, é através dos grupos de apoio, 
inclusive intervenções psicoterápicas, pois a Psicologia está intimamente ligada a esta ressignificação de valores e crenças (PINTO; PICON, 2009). Estes preparam o(s) adotante(s) para esta experiência de vida, auxiliam as famílias no convívio diário e ampliam os olhares da adoção para o melhor interesse das crianças/adolescentes (LEVY; DINANA; PINBO, 2009; SANTOS et al., 2011; OLIVEIRA; MAGALHÃES; PEDROSO, 2013; BORTOLATTO; LOOS; DELVAN, 2016).

\section{Considerações Finais}

A análise dos artigos encontrados em periódicos nacionais possibilitou verificar como a temática da adoção tem sido investigada. Evidencia-se a necessidade de estudos com diferentes públicos, no que tange a representação social da adoção, para que se possa identificar como o tema é pensado e, daí, possibilitar orientações e difusão de informação com vistas ao desenvolvimento de uma cultura da adoção, sobretudo favorecendo o "melhor interesse da criança e adolescente" garantindo, dessa forma, o direito constitucional de viver em família.

Ao analisar os artigos, emergem categorias que possibilitam uma melhor compreensão dos mesmos, bem como identificar as relações possíveis entre os resultados dos artigos. Neste sentido, identificou-se que os artigos associados às categorias "Especificidades da adoção", "Relação adotiva" e "adultos" possuem uma relação direta com os que foram vinculados à categoria "Representações sociais”, ou seja, há conexão entre adotar um perfil atípico, elaborar uma relação adotiva saudável e naturalizar a experiência da adoção com a ressignificação proporcionada por grupos de apoio e a promoção de discussões, seja na sociedade ou no meio acadêmico, sobre o assunto. Esta relação corrobora com o entendimento que atuar na difusão de informações sobre adoção é um caminho adequado para se trabalhar a reestruturação do tema adoção e, consequentemente, nas representações sociais.

Já a Psicologia, em si, vem pensando, também, sobre a temática, em como encontrar formas de contribuir para a propagação de informação, além de buscar recursos para se aperfeiçoar. Os estudos de validação de instrumentos que visam a um perfil de adotante mais apto (DUGNANI; MARQUES, 2011; BRASILEIRO et al., 2017) e a proposta de psicoterapia em grupo para preparar futuros pais adotivos (PINTO; PICON, 2009), são exemplos de ações voltadas para o melhoramento das representações que adotantes formam sobre a adoção. Os instrumentos dos estudos de validação possibilitam um entendimento da motivação dos respondentes para adotar, e assim encontrar caminhos de encaixe com as necessidades das crianças e adolescentes que esperam pela adoção, além de identificar indivíduos que ainda precisam de mais conhecimento sobre esse assunto antes de iniciarem de fato o processo adotivo. Já a proposta psicoterápica vem ao encontro dessa necessidade de aprendizado que os futuros pais adotivos demonstram ao longo do processo de adoção. A psicoterapia atua em cima da capacitação dessas pessoas sobre misticismos e senso comum, que poderão enfrentar ou que elas mesmas tenham, enquanto há o desenvolvimento afetivo com o filho adotivo. Ou seja, se implementa a ressignificação da temática aqui discutida. 


\section{REFERÊNCIAS}

APOLINÁRIO, A. S. A. C.; ANTUNES, M. C. Adoção de crianças e adolescentes soropositivos. Boletim Academia Paulista de Psicologia, v. 35, n. 89, p. 325-349, 2015.

AYRES, L. S. M. Adoção e mídia televisiva: a telenovela Amor à vida em análise. Arquivos Brasileiros de Psicologia, v. 68, n. 3, p. 92-109, 2016.

BAPTISTA, J.; SOARES, I.; HENRIQUES, M.; O impacto da adoção no desenvolvimento da criança. Edições Colibri, v. 27, n. 2, p. 63-79, 2013.

BARBOSA-DUCHARNE, M. BARROSO, R. Análise Intergeracional do Processo de Adoção: Avós, Pais e Filhos. Revista Amazônica, v. 5, n. 1, p. 183-207, 2012.

BORBA, M.C.L Os bastidores da adoção: o luto do "esperado" filho biológico. Dissertação de mestrado em Psicologia. Univ. Católica de Pernambuco. 2015. Disponível em: http://tede2.unicap. br:8080/handle/tede/231.

BORTOLATTO, M. O.; LOOS, V. N.; DELVAN, J. S.; Grupos de estudo e apoio à adoção e o sucesso das adoções. Revista do Departamento de Ciências Humanas, n. 48, 2016.

BRASILEIRO, T. C.; FÔNSECA, P. N.; GOUVEIA, R. S. V.; CARVALHO, T. A.; GOUVEIA, V. V.; Escala de atitudes frente à adoção: Construção e validação. Psico, v. 48, n. 1, p. 50-60, 2017.

BRODZINKY, D. SCHECHTER, D. Psychological and Academic Adjustmente in Adopetd Children. Journal of consulting and clinical psychology, v. 5, p. 582-590, 1984.

CASSIN, W. C.; JACQUEMIN, A. O Psicólogo judiciário e a cultura da adoção: limites contradições e perspectivas. Anais [...] Ribeirão Preto: FFCLRP.USP, 2001.

COUTO, O. H. C. Os caminhos cruzados da adoção: do abandono precoce à última esperança.

Reverso, v. 36, n. 68, p. 63-69, 2014.

COSTA, L. T. M.; KEMMELMEIER, V. S.; O olhar de futuros pais sobre o processo de adoção.

Psicologia Argumento, v. 31, n. 72, p. 187-196, 2013.

COSTA, N.; ROSSETTI-FERREIRA, M. C. Tornar-se pai e mãe em um processo de adoção tardia.

Psicologia: Reflexão e Crítica, v. 20, n. 3, 2007.

DANTAS, F. S. S; FERREIRA, S. P. A. Adoção tardia: produção de sentidos acerca da paternagem e filiação em uma família homoafetiva. Temas em psicologia, v. 23, n. 3, p. 593-606, 2015.

DUCHARNE, B. M. Identidade, Adoção, identidade adotiva. Cidade Solidária, v. 15, n. 27/28 p. 98-103, 2012.

DUGNANI; K. C. B., MARQUES, S. L. Construção e validação de instrumento para prática interventiva na adoção. Paidéia, v. 21, n. 50, p. 317-328, 2011.

EBRAHIM, S. G. Adoção tardia: altruísmo, maturidade e estabilidade emocional. Psicol. Reflex. Crit., v. 14, n. 1, p. 73-80, 2001.

FARAJ, S. P. et al. "Quero Entregar meu Bebê para Adoção": O Manejo de Profissionais da Saúde.

Psicologia: Teoria e Pesquisa, v. 32, n.1, p. 151-159, 2016.

GILBERTI, E. Fertilización Asistida y Novela Familar Vul. (Eds). La Adopción. Nuevos enigmas en la clínica. Buenos Aires: Sulamericana, 1999. 
HOKBERGEN, R., WALRAVEN, M. KOHNTAMM, X. Early Intervention in Adoptive Families: supporting maternal sensitive responsiveness, infant-mother attachment and infant competence.

Psychology and Psychiatry and Allied disciplines, v. 38, p. 1039-1050, 1997.

LEVINZON, G. K. A curiosidade na adoção: terreno pantanoso ou saúde psíquica?. Densidades, v. 3, n.7, p. 10-20, 2015.

LEVY, L.; DINANA, S.; PINBO, P; G; R. O grupo de reflexão como estratégia de promoção de saúde com famílias adotivas. Psicologia da Saúde, v. 17, n. 1, p. 39-42, 2009.

LEVY, L.; PINHO, P. G. R.; FARIA, M. M.; "Família é muito sofrimento": um estudo de casos de "devolução" de crianças. Psico, v. 40, n. 1, p. 58-63, 2009.

MACEDO, L. E. M. L. A dinâmica perversa na adoção: interrogando sobre filiação. Revista

Latinoamericana de Psicopatologia Fundamental, v. 17, n. 3, p. 696-705, 2014.

MARTINS, B. M. C.; FARAJ, S. P.; SANTOS, S. S.; SIQUEIRA, A.C. Entregar o filho para adoção é abandoná-lo? Concepções de profissionais da saúde. Psicologia ciência e profissão, v. 35, n. 4, p. 1294-1309, 2015.

MAUX; A. A. B. DUTRA, E. Do útero à adoção: a experiência de mulheres férteis que adotaram uma criança. Estudos de Psicologia, v. 14, n. 2, p. 113-121, 2009.

MAUX, A. A. B.; DUTRA, E. A adoção no Brasil algumas reflexões. Estudos e Pesquisas em Psicologia, v. 10, n. 2, p. 356-372, 2010.

MERÇON-VARGAS, E; ROSA, E. M; DELL'AGLIO, D. Adoção Nacional e Internacional: Processos proximais no período de convivência. Salud e Sociedad, v.2, n.3, p. 268-283, 2011.

MERÇON-VARGAS, E; ROSA, E. M; DELL'AGLIO, D. Adoção Nacional e Internacional: Significados, Motivações e Processos de Habilitação. Revista da SPAGESP, v. 15, n. 2, p. 12-26, 2014.

MOZZI, G.; NUERNBERG, A. H. Adoption of Children With Disabilities: A Study With Adoptive Parents. Paidéia, v. 26, n. 63, p. 101-109, 2016.

OLIVEIRA, M. L. S.; MAGALHÃES, C. M. C.; PEDROSO, J. S.; Família adotante: estudo de caso de adoção tardia. Revista Brasileira de História \& Ciências Sociais, v. 5, n. 9, p. 22-36, 2013.

OTUKA, L. K.; SCORSOLINI-COMIN, F.; SANTOS, M.A. A configuração dos vínculos na adoção: uma atualização no contexto latino-americano. Revista Brasileira de Crescimento e Desenvolvimento Humano, v. 19, n. 3, p. 475-486, 2009.

OTUKA, L. K.; SCORSOLINI-COMIN, F; SANTOS, M. A. Adoção suficientemente boa: experiência de um casal com filhos biológicos. Psicologia: Teoria e Pesquisa, v. 28, n. 1, p. 55-63, 2012.

PEREIRA, C. R.; TORRES, A. R. R.; FALCÃO, L.; PEREIRA, A. S.; O Papel de Representações Sociais sobre a Natureza da Homossexualidade na Oposição ao Casamento Civil e à Adoção por Famílias Homoafetivas. Psicologia: Teoria e Pesquisa, v. 29, n. 1, p. 79-89, 2013.

PINTO, M. C. N.; PICON, P. Adoção: proposta preliminar para uma abordagem psicoterápica cognitivocomportamental para pais adotantes. Revista Brasileira de Terapias Cognitivas, v. 5, n. 1, 2009.

PIVA, M. Em nome do filho. Passo Fundo: Ed. UPF. 2002.

PONTES, M. L. S.; et al. Adoção e exclusão insidiosa: o imaginário de professores sobre a criança adotiva. Psicologia em Estudo, v. 13, n. 3, p. 495-502, 2008.

SANTOS, C. P; FONSECA, M. C. S. M; FONSECA, C. M. S. M. S; DIAS, C. M. S. B. Adoção por pais solteiros: desafios e peculiaridades dessa experiência. Psicologia teoria e prática, v. 13, n. 2, p. 89-102, 2011. 
SHIFF, R., ZORAN, N. SHULMAN, S. International and domestic adoption: child, parents, and family adjustment. International Journal Behavioral Development, v. 20, p. 109-129, 1997.

SILVA, C. L.; BENETTI, S. P. C. Adoção da criança maior: um estudo do processo filiativo. Estudos de Psicologia, v.32, n.1, p.121-127, 2015.

SILVA, J. A.; Adoção de crianças maiores: percepções e vivências dos adotados. Psicologia em Revista, v. 16, n. 2, p. 434-436, 2010.

SILVA, L. A.; MESQUITA, D. P.; CARVALHO, B.G.E.; Investigando o processo de adoção no Brasil e o perfil dos adotantes. Revista de Ciências Humanas, v. 44, n. 1, p. 191-204, 2010.

SILVA, M. E. S. da. Compreendendo a adoção: um estudo com moradores de Aracaju (SE), Brasil. Pesquisas e Práticas Psicossociais, v. 4, n. 2, p. 213-220, 2010.

SONEGO, J. C.; LOPES, R. C. S. A experiência da maternidade em mães adotivas. Aletheia, v. 29, n.1, p. 16-26, 2009.

SZEJER, M.; STEWART, R. Nove meses na vida da mulher. São Paulo: Casa do Psicólogo,1997.

TAYLOR, E.; RUTTER, M. HERSOV, L. (eds). Child and Adolescent Psychiatry: Modern Approach (3rd edn). Oxford: Blackwell Scientific Publications. 1995.

VALÉRIO, T. A. M.; LYRA, M. C. D. P. A construção cultural de significados sobre adoção: um processo semiótico. Psicologia e Sociedade, v. 26, n. 3, p. 716-725, 2014.

WEBER, L. Pais e filhos por adoção no Brasil. Curitiba: Juruá, 2003. 
